\title{
Recolonization dynamics in areas disturbed by bottom fishing gears
}

\author{
F. Pranovi ${ }^{1}$, O. Giovanardi ${ }^{2} \&$ G. Franceschini ${ }^{2}$ \\ ${ }^{1}$ Dipartimento Scienze Ambientali, Università di Venezia, Campo della Celestia, Castello 2737XB, 30122 Venezia, \\ Italy \\ ${ }^{2}$ Istituto Centrale per la Ricerca scientifica e tecnologia Applicata al Mare (ICRAM), V.le Stazione, 5, 30015 \\ Chioggia (VE), Italy
}

Key words: macrobenthos, recolonization dynamics, anthropic impact, Adriatic Sea, Lagoon of Venice

\begin{abstract}
Results of two investigations on the effects of disturbance on benthic communities in lagoon and coastal areas, caused by bottom fishing-gears ('hydraulic dredge' for clams and 'rapido', a kind of beam-trawl for soles and scallops employed in the Northern Adriatic sea), are given. Such gears, although characterised by different features and targets, have similar effects on the sea bottom: both produce deep furrows (7-13 cm for the 'rapido', up to $20 \mathrm{~cm}$ for the 'hydraulic dredge'), thus affecting the texture of the bottom. In 1992 ('hydraulic dredge') and in 1995 ('rapido') two different research projects were carried out; samples of benthos were collected immediately after the passage of the gears and at fortnightly-intervals, in treated and control areas. This allowed study of the modifications of the macrobenthic communities and investigation of the short and medium-term (dredge: 60 days, 'rapido': 15 days) progression of the recolonization processes in the disturbed areas. These dynamics have been analysed by giving emphasis to the species and to their time-space fluctuations. It has been found that characteristically 'non-opportunistic' species can assume an opportunistic behaviour during the initial phase of the recolonization processes of the disturbed areas.
\end{abstract}

\section{Introduction}

Results of studies on the structure of marine ecosystems, the relationships among their components and the temporal evolution of such relationships have been of increasing importance. In addition to natural disturbance, human activities have the potential to greatly modify aquatic ecosystems. Particularly, the interaction between the benthos and the abiotic component of the ecosystem has been the subject of numerous studies, both in terms of structural relationships (Sutherland, 1974; Commito, 1982; Ambrose, 1984a; Ambrose 1984b; Valderhaug \& Gray, 1984) and recovery following events of anthropic disturbance (Dean \& Haskin, 1964; Leppäkoski, 1975; Rosenberg, 1976; Pearson \& Rosenberg, 1978; Hily, 1983; Bonsdorff et al., 1984). Chemical stresses as a consequence of pollution and dredging activities are just two examples of anthropic disturbance able to cause a drastic reduction of a benthic population, giving origin to permanent or temporary changes in the environmental abiotic features (Poiner \& Kennedy, 1984; Bonvicini Pagliai et al., 1985).

Among different anthropic activities, the trawling fishery appears not only to have a direct impact on its target species, but also on benthic communities as a whole, and on the physical environment in which they live.

The effects of bottom-fishing gears on sea-bottom morphology and its communities have been assessed in many studies mainly carried out in the North Sea (Bridger, 1970; Bridger, 1972; Pickett, 1973; Reise, 1982; de Groot, 1984; ICES, 1988; Rees \& Eleftheriou, 1989; BEON, 1990; Hutchings, 1990; Bergman \& Hup, 1992; Jones, 1992; Hall, 1994; Kaiser \& Spencer, 1996). These studies provided evidence of remarkably heavy stress on epi- and endofauna and physical disturbance on the seabed. 
The Northern Adriatic Sea is a large trawlable seabed where different types of Mediterranean bottom-fishing gears are used by the commercial fleet. A concentration may cause a high fishing pressure on the bed. This has been noted in the area off Chioggia and, to a lesser extent, inside the Venice Lagoon. In the framework of two different research projects on the effects of bottom-fishing gears in the Chioggia area, our attention has been focused on the hydraulic dredge (Pranovi \& Giovanardi, 1994) and the 'rapido' (a type of gear similar to a beam-trawl, only used in the Adriatic Sea) (Giovanardi et al., in prep.). The aim of this paper is to give a preliminary description of the short- to medium-term progression of the recolonization processes in two disturbed areas (one inside the Venice Lagoon and an other in the Adriatic Sea). In order to analyse the recolonization pattern of two different habitats disturbed with two different kind of fishing gears, data collected during the two research projects have been compared.

\section{Material and methods}

The two studies have been conducted in the Venetian area (Northern Adriatic Sea).

The study on the effects of the action of the hydraulic dredge was done in 1992, in a $1.5 \mathrm{~m}$ deep silty-sand area (sand 65\%; silt 23\%; sediment organic content $2.0 \%$ ) located in the central basin of the Venice Lagoon (near the port of Malamocco, Figure 1). Two neighbouring zones were identified: one was regularly dredged by the commercial fishery fleet (zone 1), whereas the second had never been dredged (zone 2). The study of the effects produced by the 'rapido' was done in 1995, in a $18 \mathrm{~m}$ deep silty area (sand $20 \%$; silt $78 \%$; sediment organic content $0.5 \%$ ) located in the in-shore zone (between the port of Malamocco and the Chioggia one, Figure 1). Experimental hauls were performed in three closed stations: st. 1 in a trawlable ground (treated with a single haul), st. 2 inside a twoyear-old off-shore long-line mussel farm - in order to avoid interference due to the trawl-fishing activities (treated with a single haul), st. 3, inside the farm as well (treated with 10 consecutive hauls).

\section{Gear description}

Hydraulic dredge: this gear is employed on the Northern Adriatic sandy coasts for the fishery of burrowing bivalve molluscs. The gear (Figure 2) consists of an iron cage (2.5-3 m wide) with rods having a $12 \mathrm{~mm}$ maximum span, several front water nozzles and two side runners. During fishing activity, the water jets (outlet pressure 1.5-3.5 bar) resuspend sediments and infaunal organisms get trapped into the cage. This fishing technique is one of the most severe in its impact on marine benthic communities, since it causes the sediment to be 'disturbed' to a $20-25 \mathrm{~cm}$ depth by producing about $15 \mathrm{~cm}$ deep furrows. Rapido: this gear, similar to a beamtrawl, consists of a rigid mouth rigged with iron teeth and a net bag where the catch is collected (Figure 2). This gear is exclusive to the Adriatic Sea and employed in the fishery of Pectinidae (Pecten jacobaeus, Aequipecten opercularis, Chlamys spp.) mainly on off-shore sandy bottoms and flatfish (Solea spp. and Platichthys flesus) on muddy bottoms closer to the coast-line. This type of gear produces about $5 \mathrm{~cm}$ deep furrows.

\section{Sampling procedure}

The experimental procedure has been set up by adapting methods used in earlier works (e.g. Hall et al., 1990).

Once the experimental area was identified, an experimental haul (or several, at station 3 of the 'rapido') was carried out by a commercial boat. The sampled area was immediately marked using special signs (such as buoys and posts) in order to allow its subsequent identification.

Sampling was done by SCUBA-diving with an air-lift device (hydraulic dredge: $0.5 \mathrm{~mm}$ mesh size bag; 'rapido': $1 \mathrm{~mm}$ mesh size bag) working on a $50 \times 60 \mathrm{~cm}$ iron frame up to a depth of $15 \mathrm{~cm}$ (hydraulic dredge: three replicates; 'rapido': five replicates) within (treatment) and outside (controls) the trawled areas. The sampling procedure was later repeated (hydraulic dredge: about 20-day-intervals, 4 times in total, $\mathrm{t} 0=3$ June $1992, \mathrm{t} 1=24$ June 1992, t2 = 15 July 1992, t3 = 5 August 1992; rapido: $\mathrm{t} 0=5$ October $1995, \mathrm{t} 1=20$ October 1995) both within treated and control areas.

All collected specimens were kept at $-15^{\circ} \mathrm{C}$ and then identified to the lowest possible level (species or, at least, genus). Average abundance were then calculated for each taxon.

\section{Statistical analysis}

Data were transformed (4th root) in order to give an equal weighting to both rare and common species. 


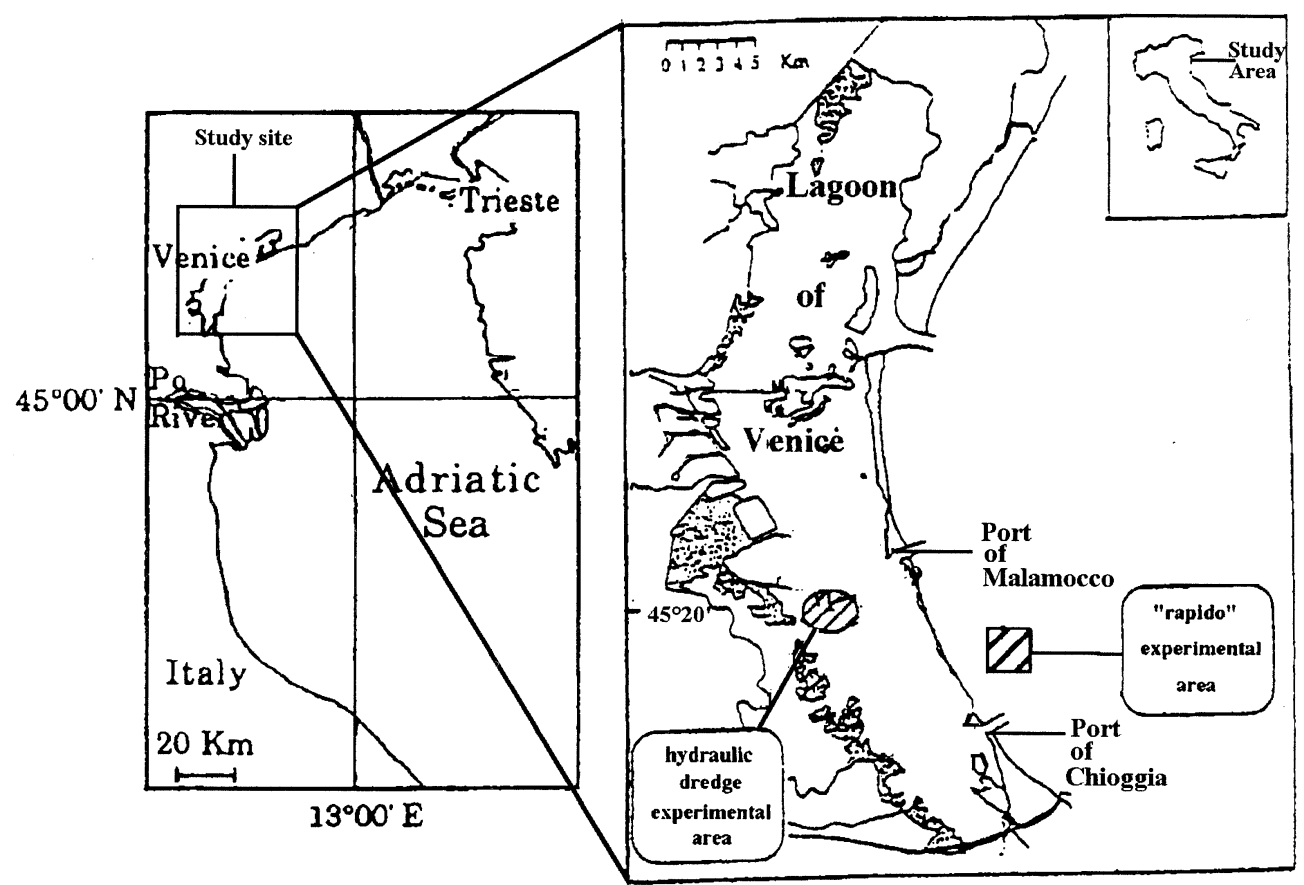

Figure 1. Location of experimental sites. The experimental area inside the Venice Lagoon, treated with the hydraulic dredge includes two adjacent zones; the experimental area treated with the 'rapido' includes two stations located inside an off-shore mussel farm and one just off it.

HYDRAULIC DREDGE

OVERALL VIEW

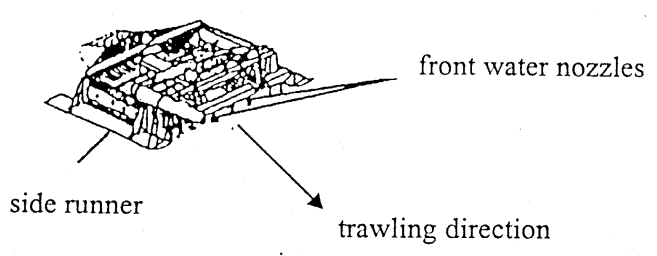

FISHING TECHNIQUE

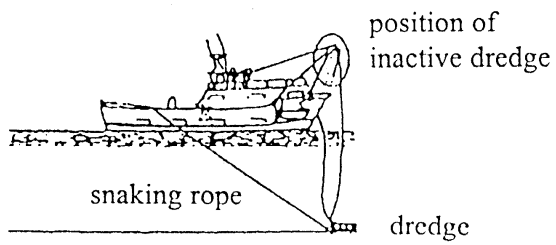

"RAPIDO"

OVERALL VIEW

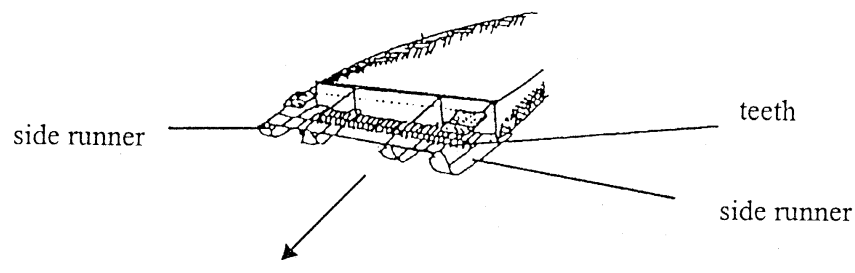

trawling direction

Figure 2. Gear descriptions and fishing techniques.

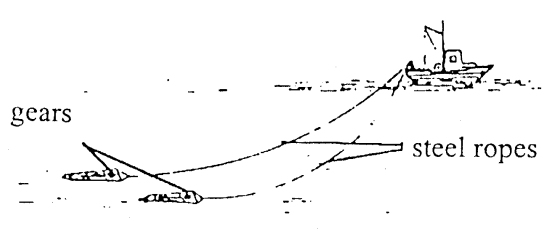


Bray-Curtis similarity matrix (Bray \& Curtis, 1957) was calculated.

In order to analyse the evolution of the populations, a MultiDimensional Scaling - MDS - (Kruskal, 1964) was applied to compare the composition of those communities and their changes.

In order to analyse the pattern of recolonization in the areas subject to the experimental hauls two methods have been used:

- the species clustering (average group linkage) by building up a dendrogram based on Bray-Curtis similarities computed on standardised abundance;

- the average dissimilarity $\delta$ among the samples has been calculated and, then, broken down into the separate contributions of each species to $\delta$. This was done using the SIMPER routine ('similarity percentage') within the software PRIMER (Clarke \& Warwick, 1994). The ratio $\delta / \operatorname{SD}(\delta)$ has been used to measure how consistently one species contributed to $\delta$ among the samples.

The trophic structure of the sampled communities has also been described in terms of qualitative dominance, computed as a ratio of abundance of the different feeding guilds.

\section{Results}

\section{$M D S$}

Reordering the samples by MDS allows the description of changes in the macrobenthic populations and in the recovery patterns.

The MDS plot of hydraulic dredge samples is shown in Figure 3. Four groups are recognisable: treated area of zone 1 immediately after the haul; all other samples collected in the zone 1; all controls and treated area immediately after the haul of zone 2; all other treated areas of zone 2.

The macrobenthic populations of zones 1 and 2 (neighbouring) seem to be quite different, as the separation between controls shows.

Moreover, there is probably a different recovery ability between the two communities after the disturbance. In zone 1 , except the $1 \mathrm{t} 0$, all other treated samples appear to be near their controls. This shows that the community rapidly begins the recovery process, resulting in an increase in similarity between treated areas and controls (after two months - $\mathrm{t} 3$ - the two situations are very close).
In zone 2 the group of treated areas, sampled at time $\mathrm{t} 1, \mathrm{t} 2$ and $\mathrm{t} 3$, is different from the respective controls.

The high similarity between the sample collected in the treated area immediately after the haul and its control shows the presence of a lag-time before the effects of disturbance can be detected.

MDS applied to the samples collected during the investigations carried out on the rapido (Figure 4) shows the existence of 4 groups: treated area of st. 1; treated areas of st. 2 and st. 3 at t0; the controls of the three stations at $\mathrm{t} 0$; the treated areas and controls at $\mathrm{t} 1$ (station 1 was not further repeated because it was outside the mussel farm, therefore not 'protected' from the commercial fisheries). The latter group shows a recovery process by the benthic population of st. 2 and st. 3. Moreover, there is some evidence of only slight differences between the area treated with a single passage of the gear (st. 2) and the one treated with more consecutive hauls (st. 3). The respective similarity of the samples (Figure 4) suggests that a great deal of the disturbance suffered by the benthic community is caused by the first passage of the gear.

\section{Average dissimilarity}

Hydraulic dredge: data related to treated areas of zones 1 and 2 have been separately compared in order to point out likely differences in the recovery pattern.

Zone 1: higher average diversity values (Table 1) are found when the to sample is involved in the comparison, with a maximum value found when the two time extremes are compared $(\delta=67.46)$. In other comparisons the difference is significantly smaller, although it never goes to 0 : between $\mathrm{t} 2$ and $\mathrm{t} 3$ samples $\delta=31.5$ (a difference of this order is found in the comparison between the samples collected at $\mathrm{t} 3$ in the treated and in control areas). The number of significant species follows the same general pattern. In the t0 vs. t 2 comparison the significant species are virtually the same as the t 0 vs. $t 1$ one. This also applies to the t0 vs. t3 comparison.

Zone 2: the situation is found to be quite different from the one in the zone 1 . The pattern is less clear and, to some extent, inexplicable. The average diversity always tends to be very high $(\delta>58)$, but, in spite of it, the species significantly contributing to $\delta$ are always between 0 and 2, as though all species contribute equally to the overall average diversity.

Rapido: the comparisons have been carried out both between the two temporal series within the 


\section{hydraulic dredge}

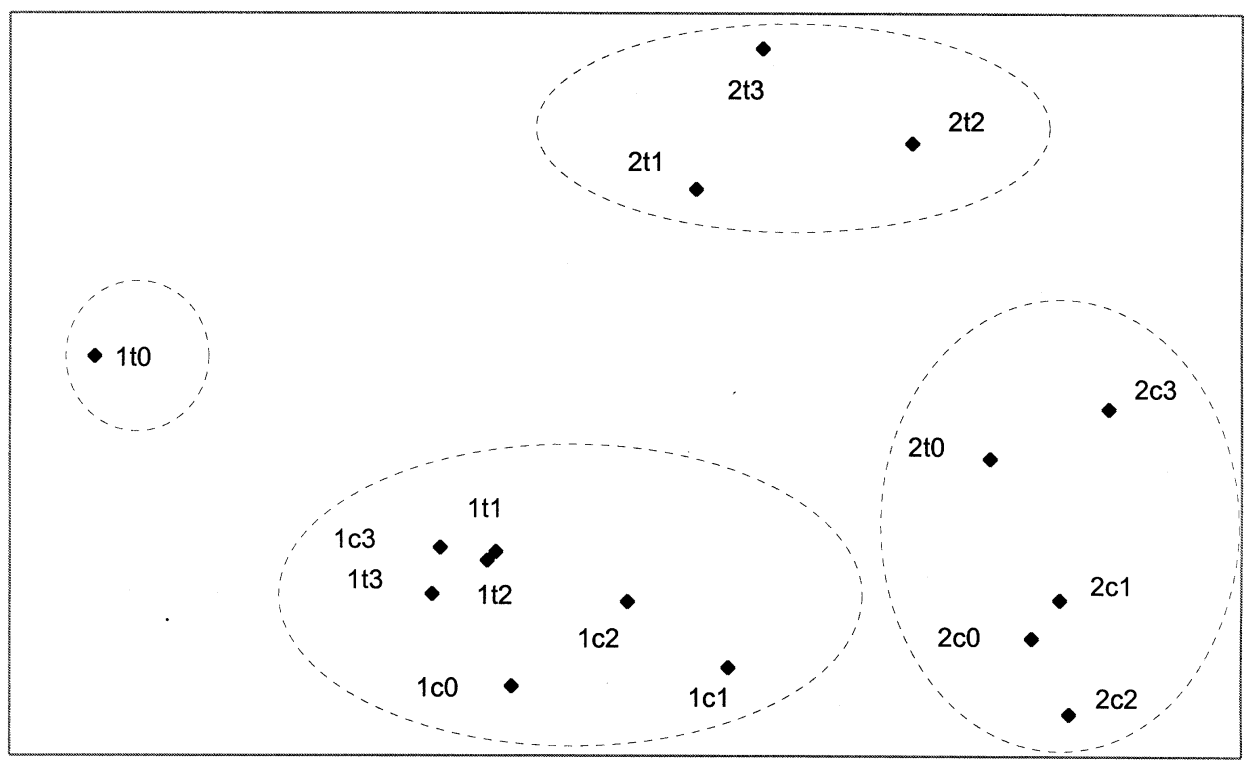

Figure 3. MDS of species abundances from samples collected in the hydraulic dredge experimental site. $(1=$ zone 1 , fishing ground; $2=$ zone 2 , never trawled by bivalve fishery vessels; $\mathrm{c}=$ control area; $\mathrm{t}=$ treated area; no. $=$ sampling date (see Materials and methods).

\section{'rapido'}

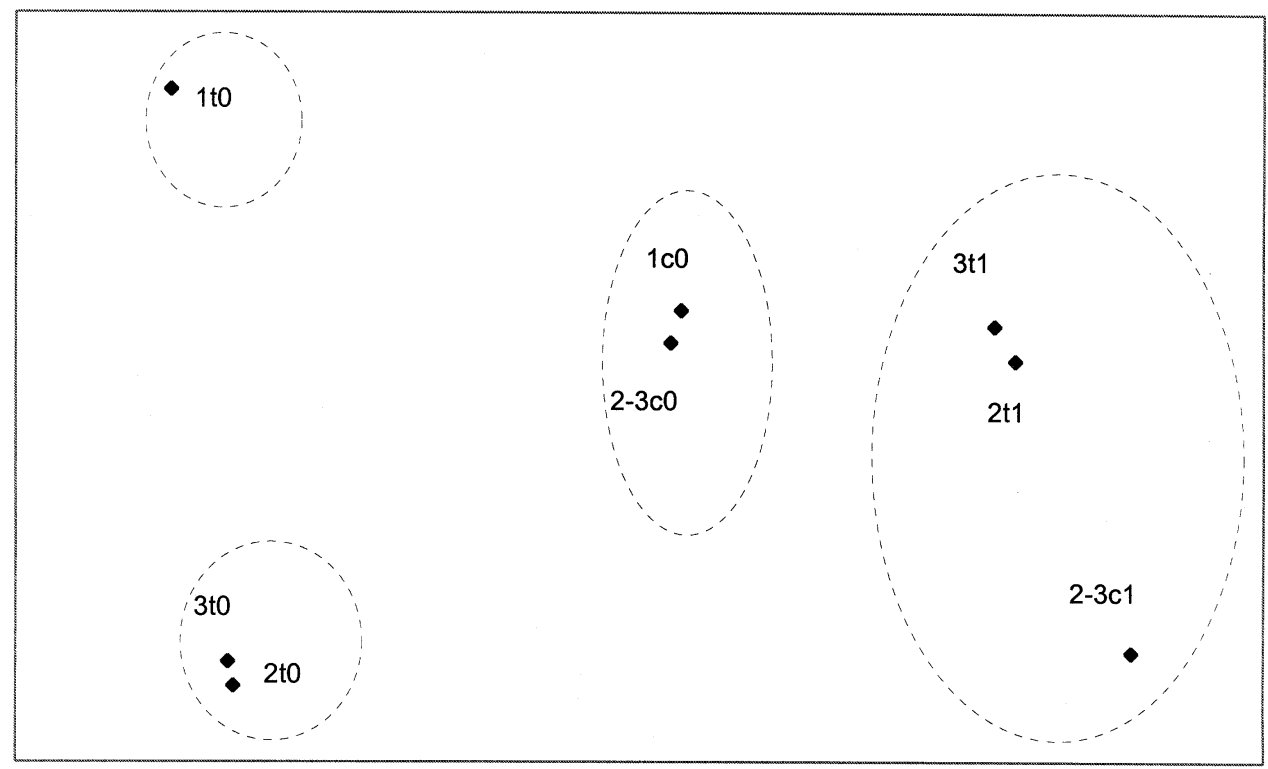

Figure 4. MDS of species abundances from samples collected in the 'rapido' experimental site. $(1=$ station outside the off-shore mussel farm; $2=$ station inside the off-shore mussel farm treated with 1 experimental haul; $3=$ station inside the off-shore mussel farm treated with 10 consecutive experimental hauls $\mathrm{c}=$ control area; $\mathrm{t}=$ treated area; no. $=$ sampling date (see Materials and methods). 
Table 1. Average diversity between samples collected in the areas treated with hydraulic dredge a) and in the 'rapido' experimental site b).

\begin{tabular}{|c|c|c|c|c|c|}
\hline \multirow[t]{10}{*}{ a) } & $\begin{array}{l}\text { DREDGE } \\
\text { zone } 1\end{array}$ & to & $\mathrm{t} 1$ & $\mathrm{t} 2$ & $\mathrm{t} 3$ \\
\hline & to & - & & & \\
\hline & $\mathrm{t} 1$ & 66.47 & - & & \\
\hline & $\mathrm{t} 2$ & 66.76 & 34.63 & - & \\
\hline & $\mathrm{t} 3$ & 67.46 & 32.67 & 31.49 & - \\
\hline & zone 2 & & & & \\
\hline & to & - & & & \\
\hline & $\mathrm{t} 1$ & 62.11 & - & & \\
\hline & $\mathrm{t} 2$ & 64.33 & 62.60 & - & \\
\hline & $\mathrm{t} 3$ & 58.96 & 58.04 & 61.22 & - \\
\hline \multirow[t]{5}{*}{ b) } & RAPIDO & treated t0 & treated $\mathrm{t} 1$ & control t0 & control $\mathrm{t} 1$ \\
\hline & treated t0 & - & & & \\
\hline & treated $\mathrm{t} 1$ & 66.57 & - & & \\
\hline & control t0 & 49.92 & 41.66 & - & \\
\hline & control t1 & 73.42 & 43.05 & 55.59 & - \\
\hline
\end{tabular}

treated area (the data related to the area treated with 1 experimental passage and those related to the area treated with several passages have been joined together because of the homogeneity of their recovery pattern) and between the two temporal series and their respective controls.

The comparison between the treated area after 15 days and its respective control shows an average dissimilarity equal to 43.1 (Table 1 ) This is due to the effect of species which are not significant in the comparison of the two temporal series of the treated area. The comparison between the two controls shows an average diversity equal to 55.6 (Table 1).

\section{Cluster analysis by species}

By employing the Bray-Curtis similarity matrix among species, a cluster analysis has been applied to both the hydraulic dredge and rapido data sets. The entire species set has been included in this analysis in order to allow evaluation of the behaviour of the less frequent as well as common species. By using $40 \%$ similarity as an arbitrary cut-off point, evidence is found as regards the presence of distinct groups, including most or all of the species, whose contribution to $\delta$ is statistically significant. In the cluster of zone 1 (Figure 5) - hydraulic dredge experiment - all the significant species (*-marked, except Hexaplex) are in the same group.
In the case of the rapido (Figure 6) the significant species ( $*$-marked) in the comparison between the two temporal situations of the treated area are found in one group, while all those significant (+-marked) in the comparison between the treated area (at t1) and respective controls are found in a second distinct group. This points out the similarity in the behaviour of such species, since it is possible to consider those species whose abundance tends to fluctuate in the same way through the different stations to be similar.

Data related to zone 2 of the investigation on the dredge are not reported since the peculiarity of the pattern shown by the population following the disturbance did not result in any significant grouping.

\section{Trophic structures}

For a better comprehension of the recolonization dynamics, the trophic population structure (abundance assembling) in the treated areas and their respective controls have been compared.

\section{Hydraulic dredge}

Zone 1 . At to the trophic structures in the treated area and its control are similar (Figure 7a). At t1, after the beginning of the recolonization process, the control and treated area show some differences. In the treated area, in fact, the prevailing group is represented by deposit feeders $(70 \%)$. In the control, the filter feeder is the most abundant group (46\%).

At $t 2$ the situation further changes, since in the treated area the filter feeder group becomes dominant, with a group distribution resembling that found in the control of the previous sampling (t1).

Finally, at $\mathrm{t} 3$, the distributions observed in the treated area and its control are found to be relatively similar as if a certain uniformity between the two zones has been reached (Figure 7a).

Zone 2. At to the pattern is the same of that of zone 1, with a similar distribution between the treated area and the control (Figure 7a); at t1 in the treated area an increase of the necrophagous and the 'others' groups is observed, while in the control deposit feeders are the most abundant group. At $\mathrm{t} 2$ the necrophagous group prevails in the treated area, while the group of the 'others' is still very abundant compared to the control. Finally, at $\mathrm{t} 3$, the distribution of the groups in the treated area is more homogeneous and similar to that of the control (Figure 7a). 


\section{hydraulic dredge}

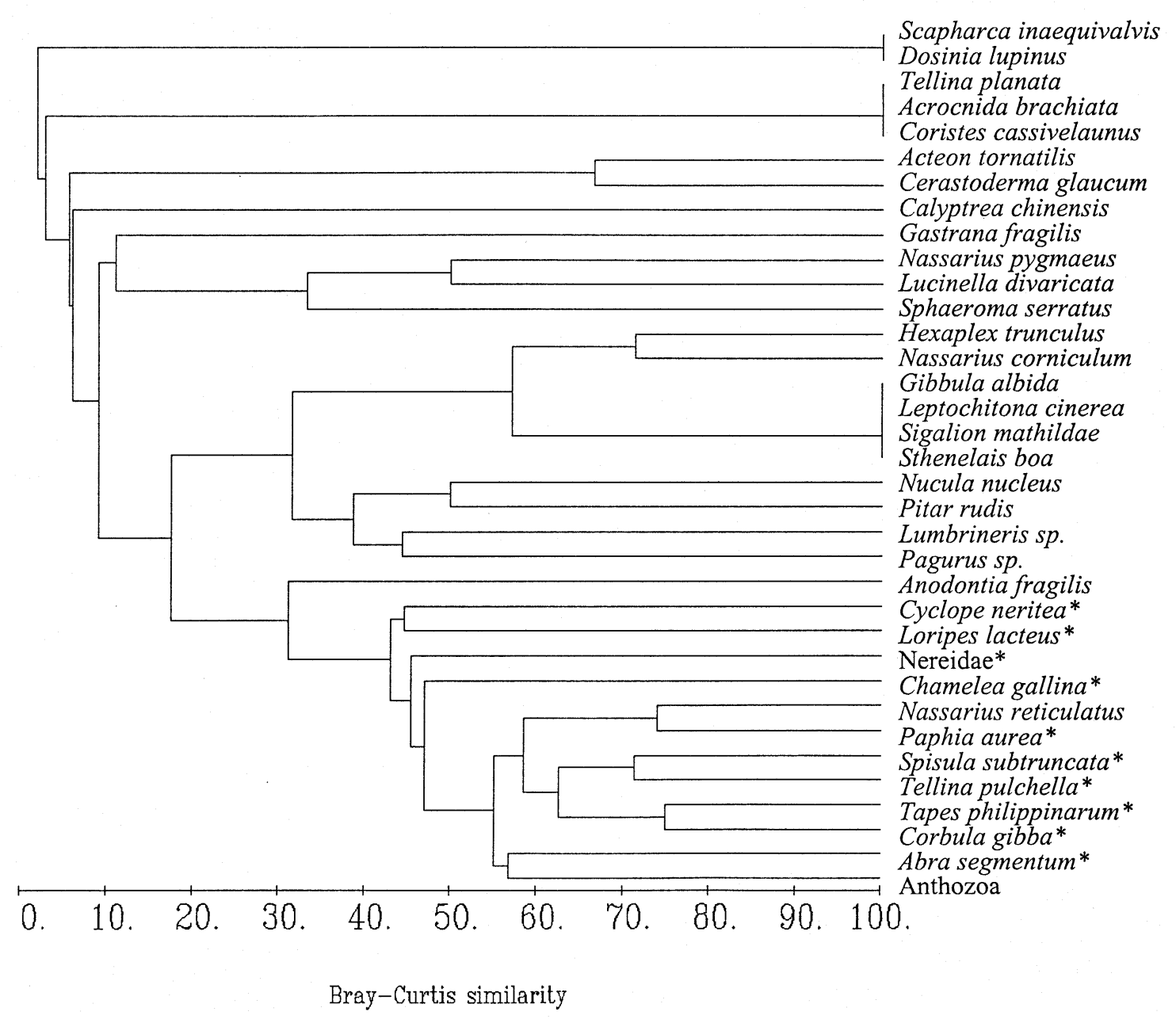

Figure 5. Cluster analysis of the samples collected in the hydraulic dredge experimental site, performed using species as variables.

\section{Rapido (Figure $7 b$ )}

The community is found to be dominated by deposit feeders, typical of muddy bottoms. All recovery processes are linked to this prevailing group; after 15 days, the distributions of feeding groups observed in the treated area are quite similar to those observed in the controls.

\section{Discussion and conclusions}

The data collected during the different investigations allows us to draw some preliminary conclusions about the effects of disturbance produced by trawl-fishing gears on the macrobenthic communities and the recolonization patterns in the Venetian areas.

The recovery time of the macrobenthic communities after this type of disturbance depends on the intensity of the disturbance itself, on hydrodynamic conditions, on bottom grain size and on the structure of the community affected by the disturbance (Kaiser $\&$ Spencer, 1996).

It has been shown that the disturbance caused by the hydraulic dredge is more severe than the one caused by the rapido, as was expected due to the structural and working differences of the gears. This fact, associated with environmental factors, has probably produced different recovery speeds. 


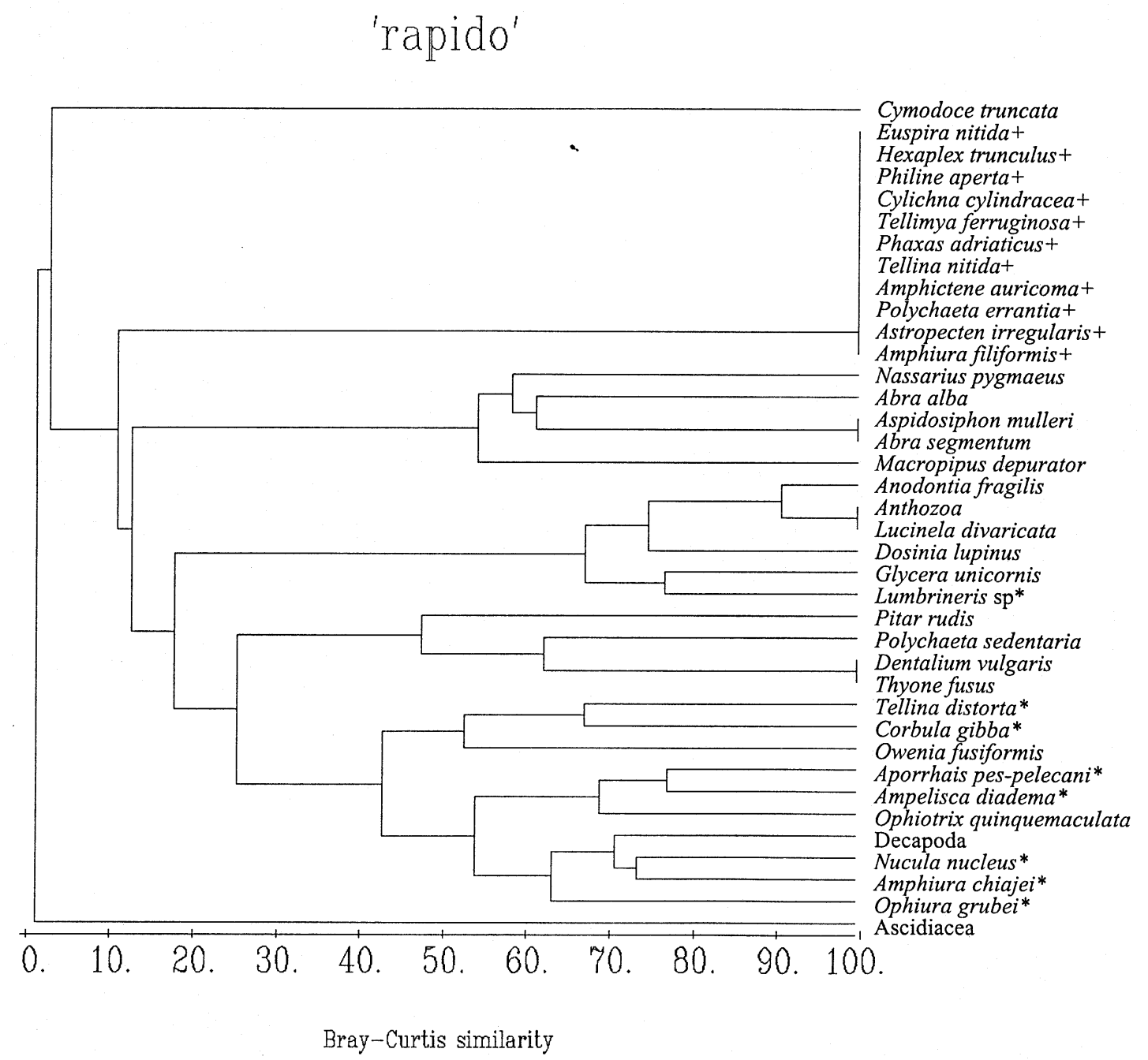

Figure 6. Cluster analysis of the samples collected in the 'rapido' experimental site, performed using species as variables.

The disturbing action of the two gears seems to have similar general features: rearrangement of the bottom with production of furrows; resuspension of the sediment, with consequent differential sedimentation of the particles according to their size ((Pranovi \& Giovanardi, 1994), in the long run this could produce changes in the grain size due to the loss of finer particles, as shown in the lagoon environment); direct action on the benthic organisms with their removal or damaging.

The direct action of both gears on the benthic population causes, as shown in the analysis of the trophic groups immediately after the experimental hauls, a non-selective reduction in the abundance of all species, both those directly captured and those re- suspended in the sediment plume behind the gear and transported by the water currents.

Successional processes following an external disturbance event can be influenced, in addition, by factors such as intensity of the disturbance, season (Sousa, 1980; Hawkins, 1981) and environmental features of 'disturbed' areas (Zajac \& Whitlatch, 1982), and even by the community structure. In the long run, this method of fishing modifies the macrobenthic community resulting in the loss of more fragile species (Bergman \& Hup, 1992; Eleftheriou \& Robertson, 1992; Bergman \& van Saintbrink, 1994; Kaiser \& Spencer, 1996; MacDonald et al., 1996), and improving its 'recovery capacity'. This would explain the different recovery and recolonization patterns shown 
a)

\begin{tabular}{|c|c|c|c|}
\hline zone 1 control to & 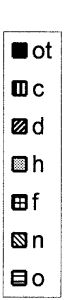 & zone 1 treated to & 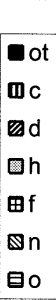 \\
\hline $\begin{array}{ll}\text { zone } 1 \text { control t3 } & \\
37 \% & 4 \%\end{array}$ & 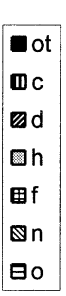 & zone 1 & 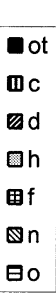 \\
\hline $\begin{array}{ll}\text { zone } 2 \text { control to } \\
7 \% 11 \%{ }_{1 \%}\end{array}$ & 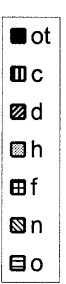 & zone 2 treated to & 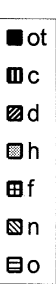 \\
\hline 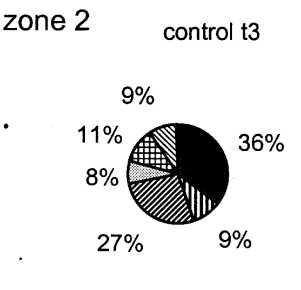 & 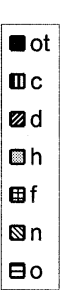 & 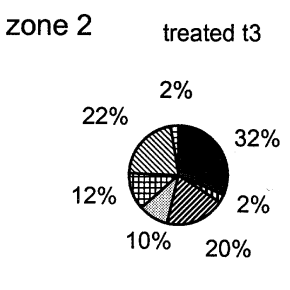 & 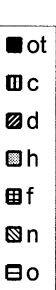 \\
\hline
\end{tabular}

b)

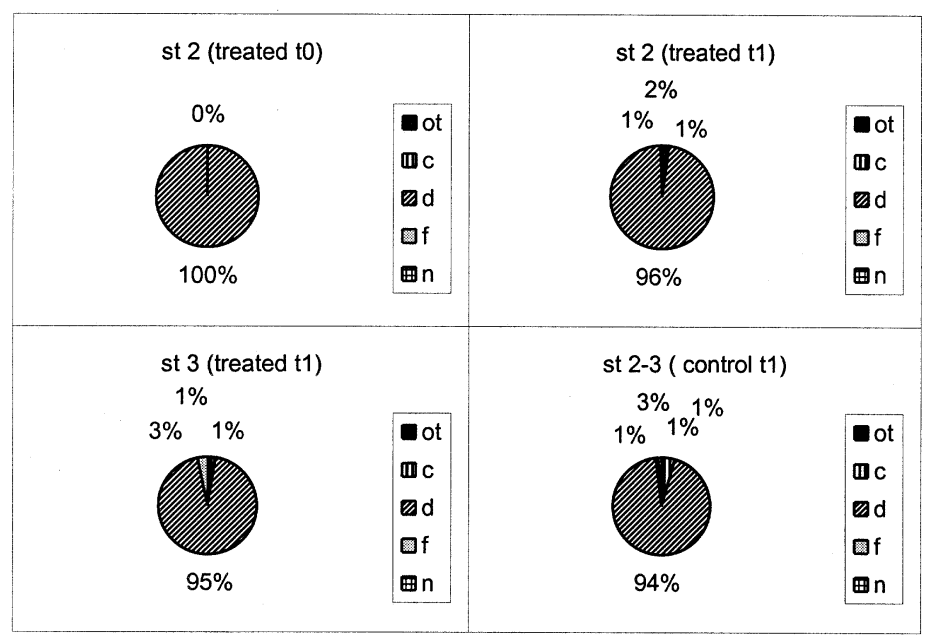

Figure 7. Trophic structure of the population in zone 1 and zone 2 of hydraulic dredge experimental site a, and in the 'rapido' experimental site $b$; at $t=0$ the stations 2 and 3 show the same trophic structure. Feeding guilds: ot $=$ other; $c=$ carnivorous; $d=$ deposit feeders; $f=$ filter feeders; $\mathrm{h}=$ herbivorous; $\mathrm{n}=$ necrophagous; $\mathrm{o}=$ omnivorous. 
in the two areas treated with the hydraulic dredge. The community of zone 2 is not 'adapted' to this type of disturbance which has therefore induced 'unexpected and unpredictable' changes. The recolonization pattern is completely different from that of zone 1 , whose population, instead, would already be 'adapted' to the disturbance produced by fishing activity. This could lend support to Sander's theory of the biologically and physically adapted community (1968), applied to a slightly different situation. Other studies (Brylinsky et al., 1994; Kaiser \& Spencer, 1996) have already emphasised that it is more difficult to prove the ability of demersal fishing gears to modify benthic communities and environment in areas subjected to frequent natural perturbations, according to the hypothesis proposed by Boesch \& Rosenberg (1981) for which the communities living in less constant environments are more resistant to disturbance.

The analysis of the recolonization dynamics shows that a certain number of species soon cover the newly available space, while the process is found to be slower for other species.

Recolonization is mainly by species with high abundance in the surrounding area, rather than specifically short-lived opportunist species (Boesch \& Rosenberg, 1981; Jones, 1992). This is indicated by the presence of both species well-known for their opportunistic behaviour, such as Corbula gibba (Pearson \& Rosenberg, 1978; Crema, 1989), and species lacking such characteristics, such as Tapes philippinarum and Paphia aurea, in the pool of species which significantly contribute to the average diversity. As a matter of fact, the two last-mentioned species, characterised by many morphological elements considered typical of a $\mathrm{K}$ strategy, are found to have an opportunistic behaviour (sensu Thistle, 1981), being able to quickly recolonize the treated area.

This scheme is also pointed out by the analysis of the trophic groups in the area treated with the hydraulic dredge where, after an initial prevalence of deposit feeders, dominated by $C$. gibba, an increase of filter feeders, mainly T. philippinarum and P. aurea, follows.

In conclusion, we state that in studies aiming to evaluate the effects of short- to medium-term trawlfishing activities it is also necessary to consider the type of community the investigation is performed on. In planning management of marine demersal resources, it must be taken into consideration that benthic communities have the capacity to adapt to an anthropic 'predictable' disturbance, but that there is also a threshold beyond which even populations consisting of 'resistant' species can collapse causing the community to become extremely simplified, with loss of its main ecological functions and inevitable negative feedback even on the target species.

Some species which are not usually considered to belong to the group of 'opportunists' can assume an opportunistic behaviour within particular situations of recolonization following a state of direct disturbance produced by fishing activities.

\section{Acknowledgements}

We thank Dr I. Lombardo, the referees who helped us to significantly improve the manuscript and Mrs Mirkka Jones for the language revision.

\section{References}

Ambrose, W. G., 1984a. Influence of residents on the development of a marine soft-bottom community. J. mar. Res. 42: 633-654.

Ambrose, W. G., 1984b. Role of predatory infauna in structuring marine soft-bottom communities. Mar. Ecol. Progr. Ser. 17: 109115.

BEON, 1990. Effects of beamtrawls fishery on the bottom fauna in the North Sea. BEON Rep. 13, 85 pp.

Bergman, M. J. N. \& M. Hup, 1992. Direct effects of beamtrawling on macrofauna in a sandy sediment in the southern North Sea. ICES J. mar. Sci. 49: 5-11.

Bergman, M. J. N. \& J. W. van Saintbrink, 1994. Direct effects of beam-trawling on macrofauna in sandy areas off the Dutch coast. In de Groot, S. J. \& H. J. Lindeboom (eds), Environmental impact of bottom gears on benthic fauna in relation to natural resources management and protection of the North Sea, NIOZ Rep. 11: 147-178.

Boesch, D. F. \& R. Rosenberg, 1981. Response to stress in marine benthic communities. In Barret, G. W. \& R. Rosenberg (eds), Stress effects on natural ecosystems, J. Wiley \& Sons, New York: 179-200.

Bonsdorff, E., O. Karlsson \& E. Leppäkoski, 1984. Ecological changes in the brackish water environment of the Finnish West coast caused by engineering works. Ophelia 3: 33-44.

Bonvicini Pagliai, A. M., A. M. Cognetti Varriale, R. Crema, M. Curini Galletti \& R. Vandini Zunarelli, 1985. Environmental impact of extensive dredging in a coastal marine area. Mar. Pollut. Bull. 16: 483-488.

Bray, J. R. \& J. T. Curtis, 1957. An ordination of the upland forest communities of Southern Wisconsin. Ecol. Monogr. 27: 325-349

Bridger, J. P., 1970. Some effects of the passage of a trawl over the sea-bed. ICES, CM 1970/B:10, Gear and Behaviour Communications, $10 \mathrm{pp}$.

Bridger, J. P., 1972. Some observations on the penetration into the seabed of tickler chains on a beam trawl. ICES, CM 1972/B:7 Gear and Behaviour Communications, 9 pp.

Brylinsky, M., J. Gibson, D. C. Gordon Jr., 1994. Impacts of flounder trawls on the intertidal habitat and community of the Minas Basin, Bay of Fundy. Can. J. Fish. aquat. Sci. 51: 650-661. 
Clarke, K. R., R. M. Warwick, 1994. Change in marine communities: an approach to statistical analysis and interpretation. Natural Environment Research Council, UK, 144 pp.

Commito, J., 1982. Importance of predation by infaunal polychaetes in controlling the structure of a soft bottom community in Maine, USA. Mar. Biol. 68: 77-81.

Crema, R., 1989. Aspetti della successione in comunità macrozoobentoniche marine di fondi mobili. SITE Atti 7: 315-320.

Dean, D. \& H. Haskin, 1964. Benthic repopulation of the Raritan River estuary following pollution abatement. Limnol. Oceanogr. 9: 551-563.

de Groot, S. J., 1984. The impact of bottom trawling on benthic fauna of the North Sea. Ocean Management 10: 21-36.

Eleftheriou, A. \& M. R. Robertson, 1992. The effects of experimental scallop dredging on the fauna and physical environment of a shallow sandy community. Neth. J. Sea Res. 30: 289-299.

Hall, S. J., D. J. Basford, N. R. Robertson, 1990. The impact of hydraulic dredging for razor clams Ensis sp. on infaunal community. Neth. J. Sea Res. 27: 119-125.

Hall, S. J., 1994. Physical disturbance and marine benthic communities: life in unconsolidated sediments. Oceanogr. Mar. Biol. Ann. Rev. 34: 179-239.

Hawkins, S. J., 1981. The influence of season and barnacles on the algal colonization of Patella vulgata exclusion areas. J. Mar. Biol. Ass. U.K. 61: 1-15.

Hily, C., 1983. Macrozoobenthic recolonization after dredging. Oceanol. Acta. Proc. 17th EMBS Brest: 113-120.

Hutchings, P., 1990. Review of the effects of trawling on macrobenthic epifaunal communities. Aust. J. Mar. Freshwat. Res. 41: $111-120$.

ICES, 1988. Report of the study group on the Effects of Bottom Trawling. ICES, CM 1988/B 56, 30 pp.

Jones, J. B., 1992. Environmental impact of trawling on the seabed: a review. New Zealand J. Mar. Freshwat. Res. 26: 59-67.

Kaiser, M. J. \& B. E. Spencer, 1996. The effects of beam-trawl disturbance on infaunal communities in different habitats. J. anim. Ecol. 65: 348-358.

Kruskal, J. B., 1964. Multidimensional scaling by optimizing goodness to fit a non-metric hypothesis. Psychometrika 29: 1-27.

Leppäkoski, E., 1975. Assessment of degree of pollution on the basis of macrozoobenthos in marine and brackish water environments. Acta Acad. Aboensi, Ser. B. 35: 1-90.
MacDonald, D. S., M. Little, C. Eno, K. Hiscock, 1996. Disturbance of benthic species by fishing activities: a sensitivity index. Aq. Conserv. Mar. Freshwat. Ecos. 6: 257-268.

Pearson, T. H. \& R. Rosenberg, 1978. Macrobenthic succession in relation to organic enrichment and pollution of the marine environment. Oceanogr. Mar. Biol. Ann. Rev., 16: 229-311.

Pickett, J., 1973. The impact of mechanical harvesting on the Thames estuary cockle fishery. MAFF Lab. Leaflet (New Series) 29: 1-27.

Poiner, I. R., R. Kennedy, 1984. Complex pattern of changes in the macrobenthos of a large sandback following dredging. I. Community analysis. Mar. Biol. 78: 335-352.

Pranovi, F., 1994. Indagine sulle comunità bentoniche di alcuni biotopi della Laguna di Venezia. Nova Thalassia 12: 43-58.

Pranovi, F. \& O. Giovanardi, 1994. The impact of hydraulic dredging for short-necked clams, Tapes spp., on an infaunal community in the lagoon of Venice. Sci. Mar. 58: 345-353.

Rees, H. L. \& A. Eleftheriou, 1989. North Sea benthos: A review of field investigation into the biological effects of man's activities. J. Cons. int. Expl. Mer 45: 284-305.

Reise, K., 1982. Long-term changes in the macrobenthic invertebrate fauna of the Wadden Sea: are polychaetes about to take over? Neth. J. Sea Res. 16: 29-36.

Rosenberg, R., 1976. Benthic faunal dynamics during succession following pollution abatement in a Swedish estuary. Oikos 27: 414-427.

Sanders, H. L., 1968. Marine benthic diversity: a comparative study. Am. Nat. 102: 243-282.

Sousa, W. P., 1980. Experimental investigations of disturbance and ecological succession in a rocky intertidal algal community. Ecol. Monogr. 49: 227-254.

Sutherland, J. P., 1974. Multiple stable points in natural communities. Am. Nat. 108: 859-873.

Thistle, D., 1981. Natural physical disturbances and communities of marine soft bottoms. Mar. Ecol. Progr. Ser. 6: 223-228.

Valderhaug, V. A. \& J. S. Gray, 1984. Stable macrofauna community structure despite fluctuating food supply in subtidal soft sediment of Oslofjord, Norway. Mar. Biol. 82: 307-322.

Zajac, R. N. \& R. B. Whitlatch, 1982. Response of estuarine infauna to disturbance. I. Spatial and temporal variations of initial recolonization. Mar. Ecol. Progr. Ser. 10: 1-14. 
